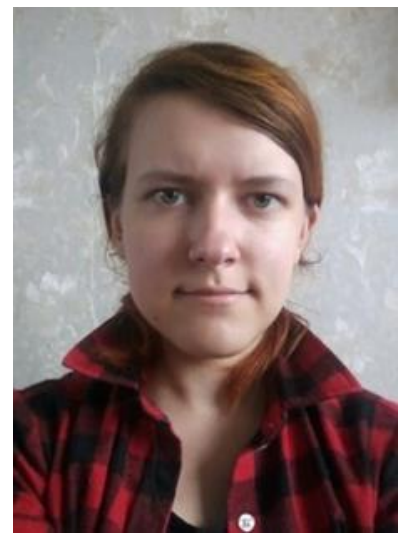

\title{
ДИНАМИКА КИСЛОТНОСТИ ПОЛЬДЕРНЫХ ЗЕМЕЛЬ
}

\author{
А.А. Гайманова, студент гр. 17-ПА/б \\ e-mail: maisa999584@gmail.com \\ ФГБОУ ВО «Калининградский государственный \\ технический университет» \\ Т.Н. Троян, канд.биол.наук, \\ e-mail: tatyana.troyan@klgtu.ru \\ ФГБОУ ВО «Калининградский государственный \\ технический университет» \\ О.М. Бедарева, д-р биол. наук, профессор, \\ e-mail: olga.bedareva@klgtu.ru, \\ ФГБОУ ВО «Калининградский государственный \\ технический университет» \\ А.С. Уманский, канд.биол.наук, \\ e-mail: anton.umanskiy@klgtu.ru \\ ФГБОУ ВО «Калининградский государственный \\ технический университет»
}

В Калининградской области расположено 80 \% всех российских польдеров, расположенных в прибрежных и аллювиальных низинах. Столетия назад здесь была создана огромная сеть открытых и закрытых осушительных сооружений, каналов. Польдерные земли делятся на три группы в зависимости от абсолютных отметок: «низкого», «среднего» и «высокого» уровня [1]. На территории Полесской низменности встречаются польдерные ландшафты всех групп. Почвы польдеров освоенные торфяно-перегнойные и торфяные низинные. Для оптимизации пищевого режима необходимо изучение трансформации агрохимических свойств почв. В связи с этим в статье рассмотрена многолетняя динамика кислотности почв и оценено современное состояние химической мелиорации польдерного участка.

Ключевые слова: низменность, польдер, кислотность, динамика, почвы

\section{ВВЕДЕНИЕ}

В условиях интенсивного развития агропромышленного комплекса к управлению земельными ресурсами приковано особое внимание, в том числе, и к польдерным землям [2, 3]. Эти участки расположены ниже уровня моря, но имеют очень хороший потенциал для выращивания сельскохозяйственных культур в целом. Около 80 \% польдерных земель России расположены на территории Калининградской области, так как область находится в зоне избыточного увлажнения. Возделывание сельскохозяйственных культур в основном осуществляется на искусственно осушенных землях. Польдеры в Калининградской области территориально встречаются в Полесском, Гурьевском, Багратионовском муниципальных округах. Но самый большой в области и России массив польдерных земель расположен на территории древней дельты Немана в Славском районе [1]. Польдерные ландшафты находятся под угрозой климатических и экономических изменений. После осушения и оптимизации пищевого режима торфяные почвы становятся 
высокопродуктивными угодьями. В связи с этим изучение трансформации агрохимических показателей освоенных низинных почв польдеров имеет научный и практический интерес.

\section{ОБЪЕКТ ИССЛЕДОВАНИЯ}

Объект исследования: агрохимические свойства почв польдера в районе насосной станции №59 между пос. Ушаковка, Июльское и Рыбкино Полесского городского округа, рядом с Восточным каналом - федеральные земли Калининградского НИИСХ - филиала ФНЦ «ВИК им. В.Р. Вильямса» (ранее земли принадлежали ОПХ «Славянское»). До 2018 г. земли находились в категории неиспользуемых сельскохозяйственных земель [4].

Количество осадков за вегетационный период не превышает 350 мм, а величина гидротермического коэффициента в этом подрайоне наименьшая. Заморозки весной в среднем прекращаются в западной части района в конце апреля, а в восточной - в начале мая. Осенние заморозки в среднем появляются во второй декаде октября (12-20). Продолжительность безморозного периода увеличивается с востока на запад (170-180 дней) [6]. Среднегодовое количество осадков - 750-800 мм.

Ландшафт территории - низменный с прибрежно-морскими равнинами.

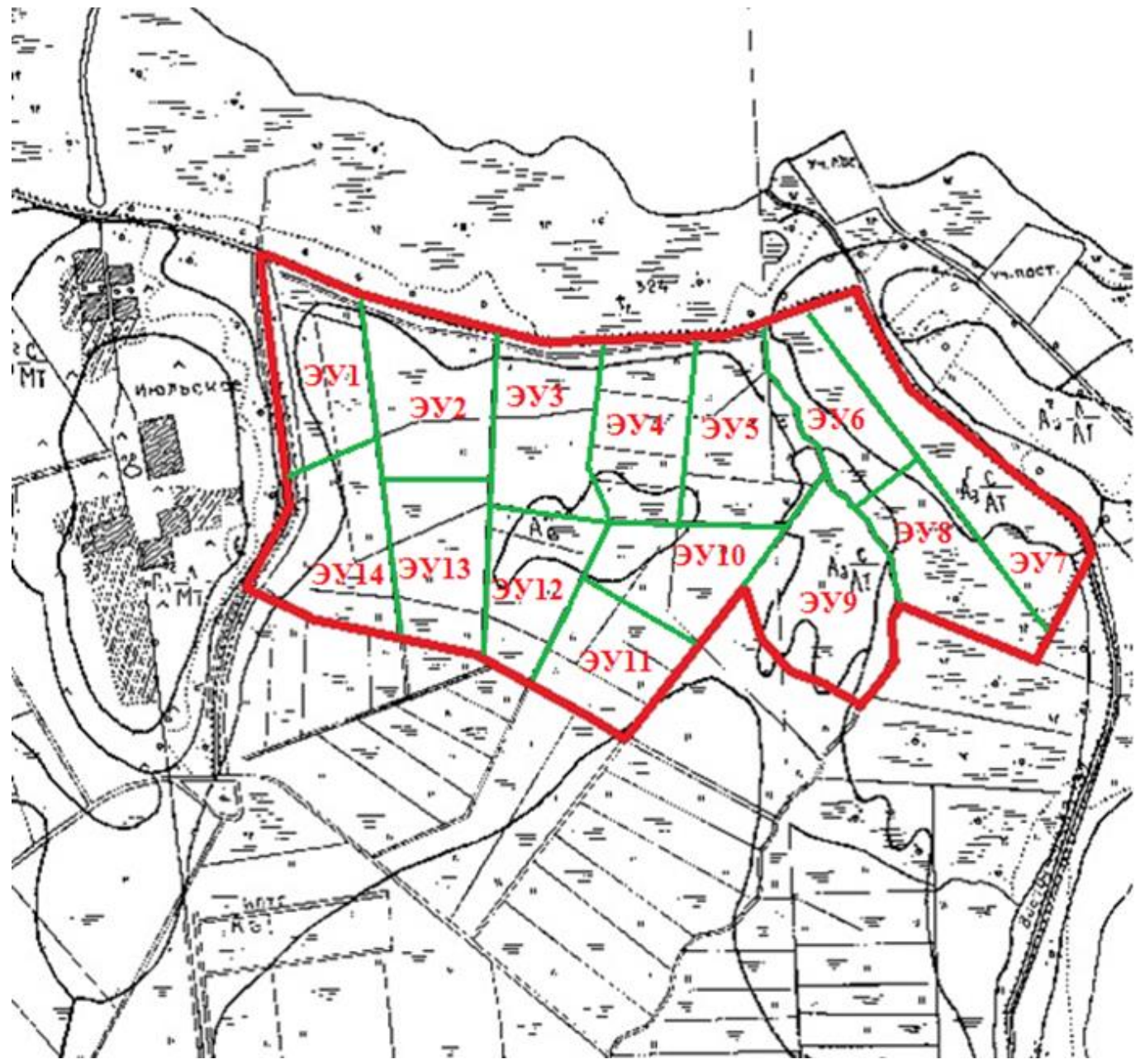

Рисунок 1 - Фрагмент почвенной карты Калининградской государственной областной сельскохозяйственной опытной станщии 1975-1976 г2. с выделенныли элементарными участками (ЭУ) (координаты участка 54.8915509, 20.9146806) [5]

По отношению к уровню моря участок расположен ниже уровня моря на 1-3 м, что подтверждается данными программы FloodMapPRO «Карта наводнений: карта высот, карта повышения уровня моря» [7]. Состояние польдерных земель имеет высокий риск затопления. 


\section{МЕТОДЫ ИССЛЕДОВАНИЯ}

Цель: изучить динамику кислотности польдерных земель Полесской низменности в районе насосной станции №60А пос. Июльское в период с 1990 по 2021 гг. до и после оптимизации водного и пищевого режимов.

Работа выполнена в рамках НИР «Растительные $u$ кормовые ресурсы Калининградской области: инвентаризация, экология, продуктивность, управление» Рег. № Код: 13.16.021.2 (ООПНДиНТИ КГТУ).

Морфологическое описание почвенного покрова польдера осуществляли по материалам почвенной карты Калининградской государственной областной сельскохозяйственной опытной станции, составленной по результатам полевого обследования и картографирования почв 1982 г. в масштабе 1:10000 на материалах аэрофотосъемки и дешифрирования 1975-1976 гг.

Оценка динамики агрохимических свойств почв проводилась на основе материалов агрохимического паспорта «Агрохимическая характеристика почв, программа повышения плодородия, рекомендации по применению средств химизации ООО «РОМАНОВСКИ АГРО» (на бывших землях ОПХ «Славянское» Полесского района» (2018 г.), архивных данных ЦАС «Калининградский» (1990, 1995, 2000 гг.) и по результатам полевых и лабораторных исследований (2021 г.).

Агрохимические показатели почв определялись в соответствии со стандартами РФ: ГОСТ 26483-85 - pH в солевой вытяжке потенциометрически; ГОСТ 26212-91 гидролитическая кислотность по методу Каппена.

\section{РЕЗУЛЬТАТЫ ИССЛЕДОВАНИЯ}

Выявлено, что колебание численных значений $\mathrm{pH}_{\mathrm{KCl}}$ на постоянных ключевых участках в период с 1990 по 2018 гг. варьировало в пределах от «слабокислых» и «близкие к нейтральнымм» в 1990 г. - $\mathrm{pH}$ 4,7-5,2 до «нейтральных» - $\mathrm{pH}>5,6$. Изменение $\mathrm{pH}$ ксl в 2018 г. обусловлено проведением масштабных культуртехнических и мелиоративных работ на польдере. В результате проведения химической мелиорации (внесение доломитовой муки) реакция среды приобрела оптимальные для сельскохозяйственных культур (яровая пшеница, яровой рапс) значения рН 6,1-7,7 (рис. 2).

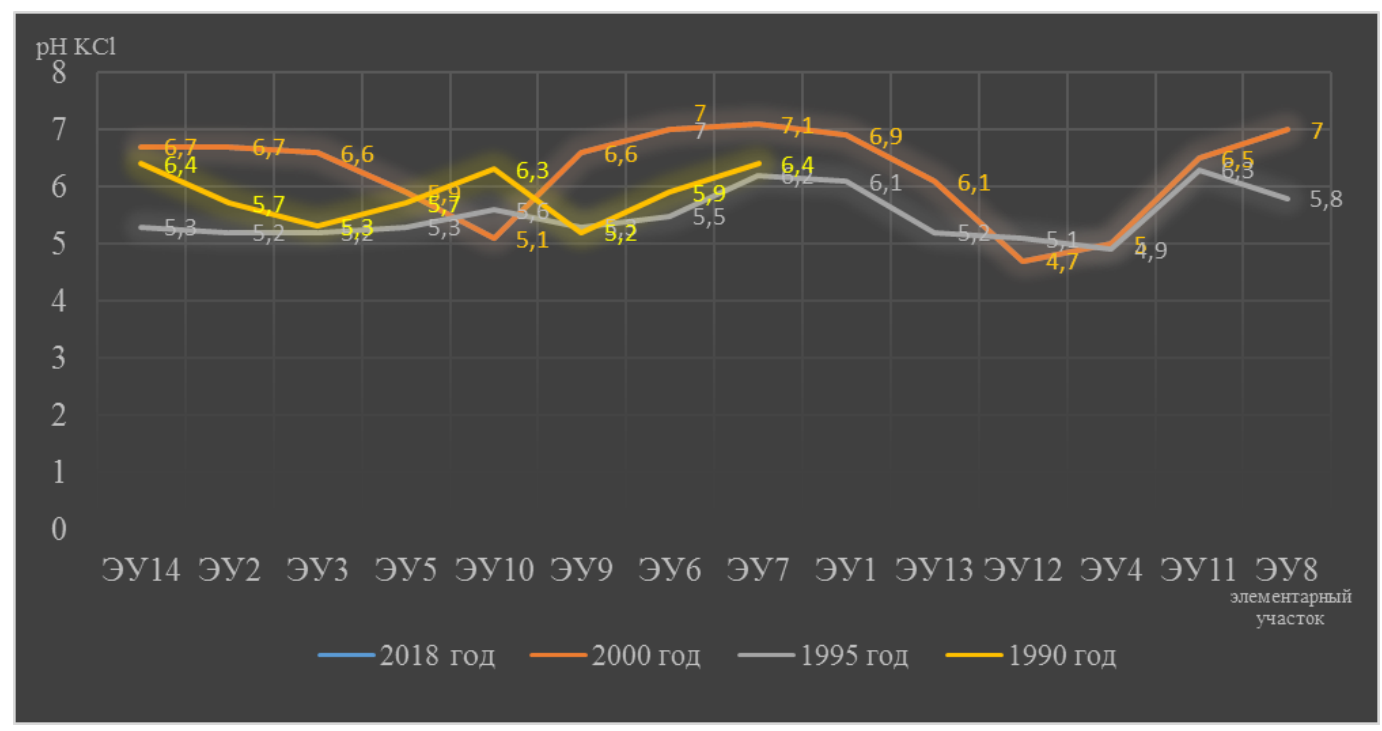

Рисунок 2 - Динамика кислотности $\left(\mathrm{pH}_{\mathrm{KCl}}\right)$

На территории исследования за весь период исследования не встречались почвы с «сильнокислой» реакцией среды (менее 4,0). Лишь по элементарным участками ЭУ12 и ЭУ4 на несколько периодов мониторинга кислотности варьирует в пределах 4,7-5,0 
(«слабокислые»). Результаты лабораторного анализа 2000 и 2018 гг. идентичны. Почти на всей территории нейтральная $\mathrm{pH}_{\mathrm{KCl}}$.

Иная ситуация представлена по гидролитической кислотности почв (рис. 3). В сравнении с 1995 и 2000, 2018 гг. по всем ЭУ, кроме ЭУ2, ЭУ3, ЭУ4, ЭУ5, ЭУ7 отмечено сильное снижение либо повышение численных значений. Пестроту данных отличает то, что в два последних периода мониторинга уровень $\mathrm{pH}_{\mathrm{H} 2 \mathrm{O}}$ в почвах «сильнощелочная».

Для изучения современного агрохимического состояния почв в 2021 г. на отдельных выборочных контурах - элементарных участках, расположенных по границе выделенного в натуре участка произведен отбор почвенных образцов. Исследованы те контуры, которые расположены в непосредственной близости от канавы перед защитной дамбой, граничащей с самой низкорасположенной мелиоративной канавой (рис. 1).

Результаты анализа почвенных проб показали, что мелиорация 2018 г. оказала существенное влияние на исследуемый показатель (рис. 4), увеличив значения $\mathrm{pH} \mathrm{c} \mathrm{6,1} \mathrm{до}$ 8,1 . Однако по контурам, граничащим с самой низкорасположенной мелиоративной канавой, наблюдается подкисление связанное, возможно, с вымыванием мелиоранта.

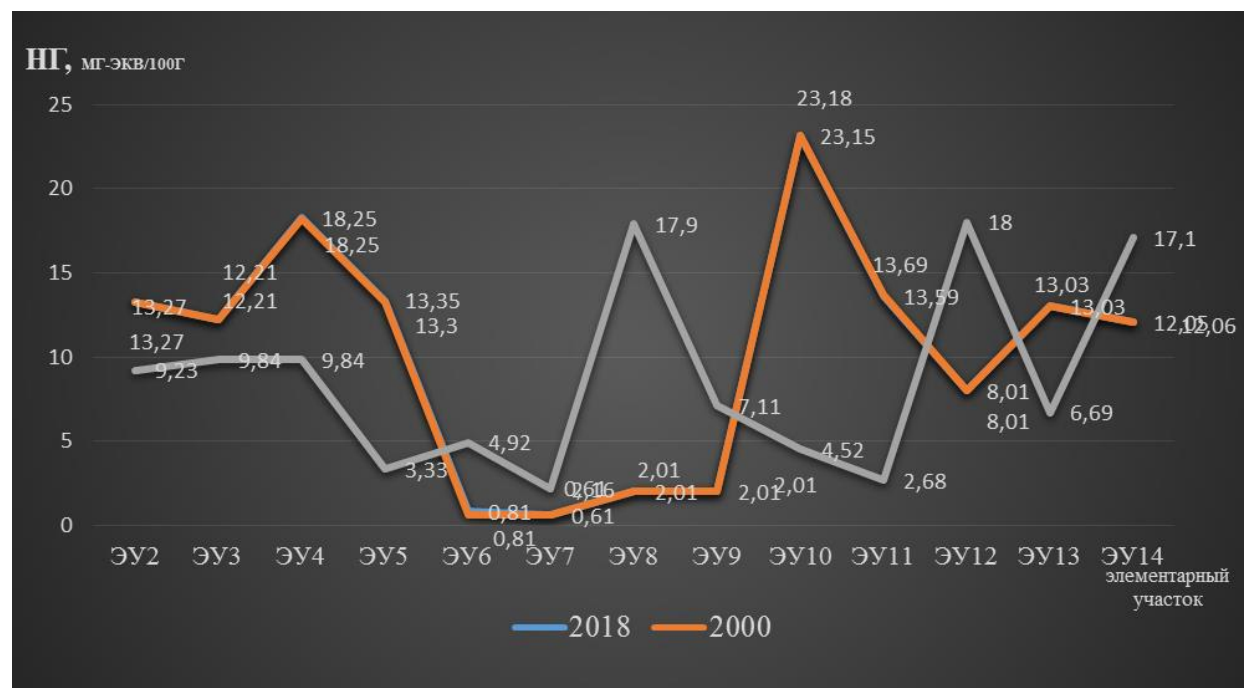

Рисунок 3 - Динамика гидролитической кислотности

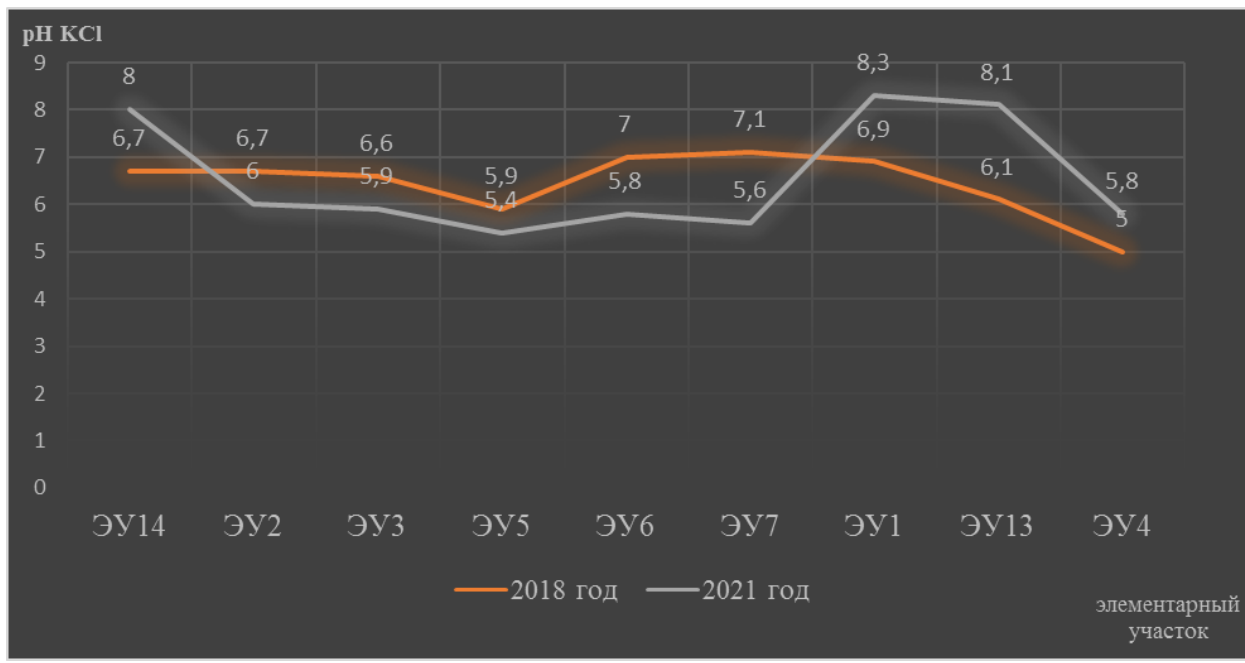

Рисунок 4 - Кислотность $\left(\mathrm{pH}_{\mathrm{KCl}}\right)$ почв в агрофитоценозе яровой пшениць

Результаты сравнительного анализа данных областной сельскохозяйственной опытной станции с данными зональной агрохимической лаборатории на участке исследования отмечена динамика повышения численных значений солевой кислотности:

1969 г.: рН (солевая) 5,5, 


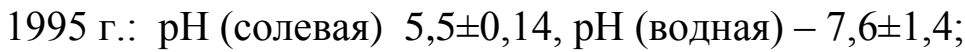

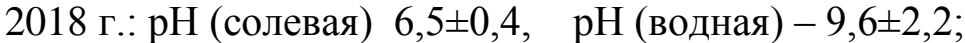

2021 г.: $\mathrm{pH}$ (солевая) 6,4 $\pm 0,22, \mathrm{pH}$ (водная) - 6,4.

Водная реакция среды имеет вариативные значения, но находящиеся в оптимальных пределах для сельскохозяйственных культур.

\title{
ЗАКЛЮЧЕНИЕ
}

Снижение рН по контурам с 1990 по 2006 гг. составило 0,5-1,5. Среднее значение снижения $-0,98$. Современные значения кислотности почв имеют щелочную реакцию среды. При таких условиях не требуется ежегодное внесение мелиоранта. Для сохранения устойчивых значений $\mathrm{pH}$ рекомендуется планировать систему химической мелиорации, так как присутствует высокий риск вымывания мелиоранта на затопляемых участках. Это позволит создать устойчивые эдафотопические условия с учетом экологических требований возделываемых культур в хозяйстве (яровые пшеница, рапс).

\section{СПИСОК ЛИТЕРАТУРЫ}

1. Панасин, В.И. Польдеры Калининградской области / В.И. Панасин, О.А. Борматенко. - Калининград: Калининградское книжное издательство, 1969. - 30 с.

2. Hildebrand P. G. de Boer. Europolders a European Program on Polder Landscape, Heritage, and Innovation / Adaptive Strategies for Water Heritage, 2019. - pp. 230-249 [Электронный ресурс]. - Режим доступа: https://link.springer.com/chapter/10.1007/978-3-03000268-8_12 (дата обращения: 16.06.21).

3. Ritchie, H. Land Use / H. Ritchie, M.Roser // Our world in data, 2019 [Электронный pecypc]. - Режим доступа: https://ourworldindata.org/land-use (дата обращения: 08.011.21).

4. Карта земельных участков [Электронный ресурс]. - Режим доступа: https://polessk.gov39.ru/content/deyatelnost/selskoe_khozyaystvo/informatsiya_po_zemle/karta_ze melnykh_uchastkov/ (дата обращения 16.06.21).

5. Публичная кадастровая карта [Электронный ресурс]. - Режим доступа: https://rosreestrmap.ru/?cadNumber=39\%3A00\%3A000000\%3A681\&lat=54.89650259196955\&ln $\mathrm{g}=20.910201072692875 \& \mathrm{zoom}=15$

6. Материалы по составлению районной геоботанической карты Полесского района. Северо-Западный государственный проектный институт по землеустройству, Калининградский филиал «Севзапгипрозем». Госагропром РСФСР, объединение «Росземпроект» (дата обращения 19.04.18).

7. Flood Map: Elevation Map, Sea Level Rise Map [Электронный ресурс]. - Режим доступа: https://www.floodmap.net/ (дата обращения 16.06.21).

\section{DYNAMICS OF $\mathrm{pH}_{\mathrm{KCl}}$ POLDER LANDS}

\author{
A.A. Gaimanova, student, \\ e-mail: maisa999584@gmail.com \\ Kaliningrad State Technical University
}

O.M. Bedareva, Doctor in Biological Sciences, Professor e-mail: olga.bedarteva@klgtu.ru;

Kaliningrad State Technical University

T.N. Troyan, assistant professor, e-mail: tatyana.troyan@klgtu.ru

Kaliningrad State Technical University 


\section{A.S. Umanskii, assistant professor, e-mail: anton.umanskiy@klgtu.ru \\ Kaliningrad State Technical University}

The Kaliningrad region contains $80 \%$ of all Russian polders. Centuries ago, a huge network of open and closed drainage structures and canals was created here. Polder lands are divided into three groups depending on the absolute marks: "low", "medium" and "high" (Panasin, Bormatenkov, 1969). All groups of polder lands from low to high levels are found on the territory of the Polesye Lowland. Using the program FloodMapPRO "Flood map: elevation map, sea level rise map" the site was studied and analyzed in relation to sea level. The article also presents studies of long-term observations of changes in the acidity of the polder area.

Key words: lowland, polder, acidity, dynamics, soils 